\title{
ENFERMAGEM MÉDICO-CIRÚRGICA
}

\section{RELATO DE UMA EXPERIENCIA NO ENSINO DE VERIFICAÇÃO DA DIURESE E DENSIDADE URINÁRIA}

\author{
Magali Roseira Boemer* \\ Branca Maria de Oliveira Santos*
}

\begin{tabular}{l|l|}
\cline { 2 - 2 } & ReBEn/02 \\
\hline
\end{tabular}

BOEMER, M.R. e Colaboradora - Relato de uma experiência no ensino de verificação da diurese e densidade urinária. Rev. Bras. Enf.; DF, 33 : 404-417, 1980.

O ensino da técnica de verificação e avaliação da diurese e densidade urinária é previsto dentro do conteúdo programático da disciplina de Fundamentos de Enfermagem, ministrada aos alunos do $2 .^{\circ}$ ano de Graduação em Enfermagem, no ciclo profissional do Currículo da Escola de Enfermagem de Ribeirão Preto, USP.

No decorrer dos anos em que temos sido responsáveis pelo ensino dessa técnica, temos sentido certa dificuldade na assimilação, pelos alunos, do conteúdo ensinado. Assim, uma aula expositiva era ministrada, seguida de demonstração prática da técnica no Laboratório de Enfermagem, sem que obtivéssemos resultados efetivos, quando era requerida do aluno a execução do procedimento durante o estágio, numa situação real. Essa dificuldade não era relacionada essencialmente à técnica propriamente dita, mas aos conhecimentos requeridos para a avaliação de uma diurese em todos os aspectos e a correlação de outros dados importantes nesta avaliação que refletissem uma ação de um profissional de enfermagem, além de uma simples execução técnica.

Havíamos observado, também, que o aluno eventualmente era capaz de executar este procedimento, desde que não fugisse da demonstração efetuada, sem capacidade de discernimento diante das diferentes situações práticas encontradas.

Assim, pensamos numa maneira de tornar esse ensino mais dinâmico, de modo a obter resultados mais efetivos. Nosso objetivo foi, portanto, proporcionar condições de aprendizagem que capacitassem o aluno a:

- adquirir conhecimentos sobre a importância da varificação da diurese e densidade urinária;

- avaliar as características da diurese;

- Professor-Assistente junto ao Departamento de Enfermagem Geral e Especializada da Escola de Enfermagem de Ribeirão Preto - USP. 
BOEMER, M.R. e Colaboradora - Relato de uma experiência no ensino de verificação da diurese e densidade urinária. Rev. Bras. Enf.; DF, 33 : 404-417, 1980.

- executar a técnica da verificação da diurese e densidade urinária;

- correlacionar a diurese e densidade urinária com outros parâmetros biológicos;

- vivenciar situações práticas específicas relacionadas ao problema da diurese e densidade urinária.

Segundo SHEAHAN 1, o fator mais importante que afeta a aprendizagem é o nível de interesse do aprendiz. Para esse autor, quanto mais se motivar o estudante, maior oportunidade ele terá de aprender e, quanto mais ativa for a aprendizagem, maior será a possibilidade de êxito.

Esse mesmo autor, em outro artigo 2 , discorre sobre métodos de ensino onde os alunos aprendem em investigações conduzidas por eles mesmos e opina que, quando aprendem fazendo, são encorajados a agir e a pensar.

As atividades aprendidas em grupos têm-se mostrado, também, em diversos campos, como as que apresentam melhores resultados no que se refere à aprendizagem.

Em uma experiência por nós realizada em $1976^{3}$, nos fundamentos no princíp:o de que o aluno se iniciaria no estudo da enfermagem, partindo do simples para o complexo, do sadio para o doente. Embasados nessa filosofia, enfatizamos aspectos de normalidade referentes a parâmetros biológicos abordados. Essa experiência de ensino tem sido recomendada por autores interessados no assunto. 456

Do exposto, podemos dizer que, na seleção de um método para o ensino da verificação da diurese e densidade urinária, tínhamos alguns fatores a considerar, quais sejam:

- o método deveria motivar a aprendizagem;

- o método deveria ser dinâmico, fazendo o aluno participar do ensino;

- as atividades deveriam ser desenvolvidas em pequenos grupos, per- mitindo a participação ativa de cada membro do grupo;

- o conteúdo a ser ensinado deveria partir do simples para o complexo, do sadio para o doente;

- a provisão de recursos materiais e humanos seria necessária, a fim de permitir ao estudante a transferência da teoria para a prática;

- a previsão de um docente permanente, responsável pelo ensino da atividade.

Assim, planejamos roteiros que guiassem o ensino, divididos em parte $\mathrm{A}$ e parte B (Anexos 1 e 2, respectivamente).

A parte A, a ser realizada em Laboratório de Enfermagem, destinava-se a grupos de dez alunos e era repetida oito vezes, perfazendo o total de alunos matriculados na disciplina de Fundamentos de Enfermagem. Cada aluno recebia um roteiro e havia sempre 0 mesmo professor que orientava as discussões, sendo utilizado um tempo médio de 90 minutos por grupo.

Inicialmente, a parte $\mathrm{A}$ do roteiro continha alguns itens onde eram relembrados os conhecimentos adquiridos em Fisiologia e Bioquímica. Seguiamse, no roteiro, itens referentes às características a serem observadas e avaliadas na urina.

O professor presente deixava que os alunos buscassem as respostas e, somente após a participação discente, complementava e/ou reforçava as respostas corretas. Essa foi a dinâmica adotada, considerando que nosso objetivo era levar o estudante a estimular o pensamento e recuperar o material armazenado na memória.

Após essas discussões, passávamos para a parte técnica propriamente dita, onde a urina a ser observada e avaliada, segundo suas características, procedia dos próprios alunos, portanto, de individuos aparentemente normais.

A parte A, aqui sintetizada, pode ser consultada na íntegra no Anexo 1. 
BOEMER, M.R. e Colaboradora - Relato de uma experıencia no ensino de verificação da diurese e densidade urinária. Rev. Bras. Enf.; DF, 33 : 404-417, 1980.

Cabe salientar que este roteiro foi previamente testado por um grugo de alunos deste mesmo ano e, após algumas pequenas modificações, foi adotado. Por ocasião desse teste já pudemos evidenciar o entusiasmo e interesse dos alunos.

Após a discussão da parte $\mathbf{A}$, passávamos para a parte $\mathrm{B}$ do roteiro, que era realizada no hospital. Desta forma, o aluno iria proceder à execução da técnica de verificação e avaliação, de diurese e densidade urinária no hospital, após ter tido experiência prévia, no Laboratório de Enfermagem, com urina procedente de indivíduos aparentemente normais.

A parte $\mathrm{B}$ do roteiro objetivava, portanto, a observação e avaliação da diurese e densidade urinária de pacientes internados em um hospital-escola e, principalmente, colocar o aluno em contato com a problemática que envolve a técnica, qual seja: identificação dos frascos de urina, troca de frascos, correlação dos resultados obtidos da mensuração e avaliação, destino da urina, etc.

A parte $B$ do roteiro pode ser consultada na íntegra no Anexo 2. Para a execução dessa parte, os alunos dirigiam-se ao hospital divididos em grupos de dez, acompanhados sempre do mesmo professor da parte A, e o ensino era realizado dentro do sanitário anexo à enfermaria, por ser este o local habitual de verificação da diurese e densidade urinário neste hospital.

Para esta parte do ruteiro, foi utilizado também um tempo médio de 90 minutos por grupo e cada aluno recebia um roteiro.

Procedíamos à avaliação da diurese e densidade, aplicando os conhecimentos adquiridos na parte $\mathrm{A}$ do roteiro $\mathrm{e}$, quando a observância de todos os aspectos técnicos da avaliação não era possível, analisávamos criticamente os impedimentos.
A dinâmica de ensino foi a mesma da parte A, ou seja, o professor deixava os alunos levantarem as dúvidas e respostas a elas e só posteriormente complementava.

Após a verificação da diurese e densidade, manuseávamos o prontuário do paciente, teritando correlacionar os dados obtidos com diagnóstico, medicação, peso, dieta, ingestão hídrica de véspera, estado emocional, valor registrado na véspera.

Consideramos essa fase de extrema importância, pois, conforme relatamos antes, nossas dificuldades em relação à técnica se estendiam também à dificuldade que o aluno apresentava, freqüentemente, em correlacionar os dados obtidos da avaliação da diurese com outros parâmetros biológicos \%/ou situações próprias do paciente.

A última fase do roteiro referiu-se ao registro das observações realizadas e orientação do paciente sobre a necessidade ou não de continuar guardando sua urina nos dias subseqüentes.

Como a introdução desta nova experiência implicou numa mudança de método de ensino, estávamos muito preocupados com os resultados, uma vez que essa representava uma inovação e monopolizava um docente aproximadamente 24 horas para sua realização.

Elaboramos, portanto, um questionário bastante simples (Anexo 3), solicitando uma avaliação por parte de cada aluno sobre a validade do método de ensino e conseqüente aprendizagem, de modo a nos fornecer subsídios para o ensino dos anos subseqüentes.

Os resultados obtidos da aplicação do questionário podem ser verificados na Tabela 1, na qual observamos que $82,6 \%$ dos alunos participaram dos dois roteiros propostos, $11,6 \%$ participaram apenas da parte $\mathrm{A}$ e $5,8 \%$ apenas da parte B.

Gostaríamos aqui de fazer um breve comentário sobre o índice de faltas 
BOEMER, M.R. e Colaboradora - Relato de uma experiência no ensino de verificação da diurese e densidade urinária. Rev. Bras. Enf.; DF, 33 : 404-417, 1980.

TABELA 1

Resultados da avaliação de um método de ensino, segundo a opinião do aluno e sua participação nos roteiros

\begin{tabular}{l|cccccccc}
\hline $\begin{array}{l}\text { Participaçao } \\
\begin{array}{l}\text { Opinião nos rotei } \\
\text { dos alunos }\end{array}\end{array}$ & $\begin{array}{c}\text { A } \\
\text { No }\end{array}$ & $\begin{array}{c}\text { B } \\
\text { ros }\end{array}$ & No & $\%$ & No & $\%$ & No & $\%$ \\
\hline Otimo & 18 & $31,6 \%$ & 0 & $0,0 \%$ & 0 & $0,0 \%$ & 18 & $26,1 \%$ \\
\hline Bom & 37 & $64,9 \%$ & 6 & $75 \%$ & 3 & $75 \%$ & 46 & $66,6 \%$ \\
\hline Razoáve1 & 2 & $3,5 \%$ & 2 & $25 \%$ & 1 & $25 \%$ & 5 & $7,2 \%$ \\
\hline Deficiente & 0 & $0,0 \%$ & 0 & $0,0 \%$ & 0 & $0,0 \%$ & 0 & $0,0 \%$ \\
\hline TOTAL & 57 & $82,6 \%$ & 8 & $11,6 \%$ & 4 & $5,8 \%$ & 69 & $100 \%$ \\
\hline
\end{tabular}

que atualmente vem ocorrendo em nosso meio estudantil. O direito a falta às aulas programadas, apesar do apoio legal, implica no fato de que experiências que requerem preparo e tempo do docente não são vivenciadas por todos os aiunos, além de que a aprendizagem não obedece a uma seqüência lógica.

Do total de alunos que participaram de ambas as partes do roteiro, podemos observar na Tabela 1 que $31,6 \%$ consideraram o método de ensino ótimo, $64,9 \%$ bom, $3,5 \%$ razoável e $0,0 \%$ deficiente.

Analisando as respostas dos alunos à questão de modificações do método de ensino, foi possível verificar que entre 69 alunos, 25 sugeriram modificações da parte $B$, não propriamente quanto ao conteúdo, mas quanto ao número de alunos por grupo, no que concordamos, que o sanitário é realmente pequeno para comportar dez alunos e um professor.

Os alunos ainda sugeriram que o ensino de outros procedimentos do programa de Fundamentos de Enfermagem fosse ministrado segundo essa metodologia.

Em nossa avaliação do método, observando o aluno em estágio, pudemos verificar ainda que, de forma subjetiva, houve diminuição da freqüência de incidentes até então comuns, tais como: esquecimento de medir a urina, desprezar a urina, quando não poderia ser desprezada; não desprezar, quando deveria ser desprezada e outros.

Do exposto, consideramos válida a experiência e sentimo-nos gratificadas frente aos resultados, que nos fazem concordar com SHEAHAN 1, quando diz que ninguém pode garantir o ensino, mas sim colocar o estudante frente à aprendizagem; que o professor pode agir como um guia, que revisões ajudam a reter informações na mente do aprendiz e que o conteúdo a ser ensinado deve ser fragmentado em partes contendo elementos de aprendizagem.

Para uma avaliação mais objetiva, poderíamos, no próximo ano, dividir a classe em dois grupos e a um ministrar o ensino desse procedimento de forma 
BOEMER, M.R. e Colaboradora - Relato de uma experiência no ensino de verificação da diurese e densidade urinária. Rev. Bras. Enf.; DF, $33: 404-417,1980$.

tradicional e a outro, na forma de roteiros, para comparação. Entretanto, temos rejeitado essa idéia por sentirmos que os alunos que recebessem o ensino da forma tradicional seriam lesados em sua aprendizagem e temonos inquirido até quanto é válido essa medida mais objetiva, se temos viven- ciado o interesse dos alunos pelo novo método e os resultados dos questionários.

Parece-nos, portanto, válido que cada professor decida sobre os métodos, recursos, interesses e motivações que favoreçam o processo ensino-aprendizagem.

\section{BIBLIOGRAFIA}

1. SHEAHAN, J. - Methods of learning; planning for teaching. Nursing Research, 26 (5) : 380-385, 1977.

2. SHEAHAN, J. - Discovery methods of teaching and team teaching. Nursing Times, 23 : 1487-89, 1976.

3. ANGERAMI, E. L. S. et alii - Relato de uma experiência de ensino na disciplina de Iniciação ao Estudo de Enfermagem. Em fase de publicação na Revista Educ. Med. Salud.
4. BARBIERI, M. A. et alii - Atenção à infância em serviço comunitário ligado à Universidade. Educ. Med. Salud, 11 (1) :50-59, 1977.

5. MONGE, C. \& VIDAL, C. A. - La ensenãnza de la medicina interna en la formación del médico. Educ. Med. Salud, 11 (4) :375-388, 1977.

6. YEPEZ, R. - Lo obstracto y lo concreto, lo disciplinario y lo interdisciplinario en la ensenãnza de las ciências fisiológicas. Educ. Med. Salud, 11 (4) :362-374, 1977.

\section{ANEXO l}

\section{ATIVIDADE PRÁTICA - VOLUME E DENSIDADE URINÁRIA}

\section{ROTEIRO - PARTE A}

Este roteiro foi preparado para vocês trabalharem em grupo. A classe será dividida por nós em grupos de dez alunos.

Vocês terão o auxílio de um professor para desenvolverem esta atividade. Atentem para a escala que designará os elementos de cada grupo, bem como Js dias, horários e local de atividade.

Vamos relembrar as aulas de Fisiologia e Bioquímica no que se referem ao produto secretado pelo rim, ou seja, a urina.

1. Qual o volume urinário médio eliminado diariamente por um adulto sadio?

R.:

2. Quais os fatores não patológicos que podem interferir no intervalo de normalidade?

R.:

3. Qual o volume médio de urina excretado em cada micção?

R.:

4. Quais os componentes normais da urina?

R. 
BOEMER, M.R. e Colaboradora - Relato de uma experıeneia no ensino de verificação da diurese e densidade urinária. Rev. Bras. Enf.; DF, 33 : 404-417, 1980.

5. Quais os componentes anormais da urina?

R.:

6. Com base nos conhecimentos sobre prefixos e sufixos, tentem definir os seguintes termos:

diurese

poliúria

oligúria

anúria

nictúria

cilindrúria

glicosúria

proteinúria

piúria

polaquiúria

disúria

7. Qual a diferença entre anúria e retenção urinária?

R.:

8. O que seria incontinência urinária?

R.:

Até agora, tratamos do que se refere a volume e componentes urinários. Entretanto, além desses, outras características da urina são passíveis de observações que poderão tornar-se relevantes na assistência de enfermagem.

Tentem citar outras características, que independam de instrumentos para avaliação:

Pois bem, já vimos que a urina é composta de água e componentes orgâmassa

nicos, portanto, deve haver uma relação - que nos forneça a densidade volume

urinária. Tentem lembrar do intervalo de valores mínimo e máximo de densidade de urina de um indivíduo normal.

R.:

Se você sabe o que é densidade, você espera encontrar em uma urina mais concentrada um valor de densidade maior ou menor que em uma urina concentrada?

R.:

É possvel medir a densidade da urina através do urodensímetro. Solicitem do professor que lhes forneça agora um urodensímetro. Familiarizem-se com ele, manuseiem-no, observem a graduação de sua escala. 
BOEMER, M.R. e Colaboradora - Relato de uma experiência no ensino de verificação da diurese e densidade urinária. Rev. Bras. Enf.; DF, $33:$ 404-417, 1980.

Acreditamos que vocês estão aptos a procederem agora à medida de volume e densidade urinária, prática essa que será muito requerida de vocês nos estágios.

Conforme dissemos no início, essa atividade é realizada em grupo. Solicitem do professor frascos e cada aluno fornecerá, na medida do possível, uma amostra de urina.

Tempo para obtenção das amostras: 10 minutos.

Não importa quantas amostras tenham sido obtidas.

Procedam à observação da urina. Descrevam suas características quanto à cor, odor, transparência e presença ou não de sedimentos.

Vamos medir o volume destas amostras. O resultado será apresentado em ml. Inicialmente devemos estar atentos à graduação do frasco ou cálice que contém a urina. Esta graduação poderá variar de acordo com o frasco e este é um detalhe importante para assegurar a exatidão da medida. Solicitem, agora, que o professor lhes forneça frascos com diferentes graduações. Todos observaram?

Pois bem. Sabemos, portanto, que a graduação do frasco que contém a urina foi feita de ..... em ..... ml.

Outro cuidado importante na leitura do volume urinário é o tipo de superfície onde o frasco está colocado. Como vocês acham que deve ser essa superfície e por quê?

R.:

Ainda existe outro cuidado, ou seja, o nível de nossos olhos deve ser compatível com o nível do líquido. E claro que, se olharmos de um nível superior ou inferior ao frasco, corremos o risco de proceder à uma leitura não exata. Vocês compreenderam?

Muito bem. Uma vez considerados todos esses aspectos, podemos finalmente efetuar a leitura.

O volume urinário que estamos observando é aproximadamente ..... ml.

Conhecemos, portanto, que o volume desta amostra de urina é de .....ml e apresenta as seguintes características:

Resta-nos agora a informação referente à densidade urinária. Vocês já manusearam o urodensímetro e vamos aprender como utilizá-lo.

Para medir a densidade, vamos transportar parte do volume urinário para uma proveta, deixando um espaço de, aproximadamente, $5 \mathrm{~cm}$ do nível superior da mesma. Observem que a escala do urodensímetro tem um valor mínimo e máximo, em geral, 1.000 a 1.060 , respectivamente.

Após transportarem a urina para a proveta, retirem a eventual camada de espuma que possa ter na superfície, utilizando para isso um pedaço de papeltoalha, de modo que a espuma não venha prejudicar a leitura.

Mantenham o urodensímetro seguro pela haste e mergulhem-no delicadamente no centro da proveta. Assegurem-se de que ele não fique aderido à pa- 
BOEMER, M.R. e Colaboradora - Relato de uma experiência no ensino de verificação da diurese e densidade urinária. Rev. Bras. Ent.; DF, 33 : 404-417, 1980.

rede da proveta. Procedam agora à leitura da escala, tendo o cuidado de adaptarem o nível de seus olhos ao nível da escala graduada do urodensímetro.

Qual é o valor indicado?

Portanto, a densidade dessa urina é

Entretanto, vocês observem agora que, na haste do urodensímetro, existe um valor numérico em graus centígrados. Isto significa que a escala do urodensímetro foi graduada à temperatura indicada por este valor. Geralmente, esta temperatura é $15^{\circ} \mathrm{C}$.

No urodensímetro que vocês têm à mão, qual é o valor indicado? ........

Parece natural que, se a temperatura da amostra de urina que temos em mãos não for igual à temperatura na qual o urodensímetro foi calibrado, tornase necesssário aplicar um fator de corrreção. A regra prática para isto é a seguinte:

- "Uma vez medida a temperatura da urina, e sabendo que o urodensímetro foi calibrado a $15^{\circ} \mathrm{C}$, para cada $3^{\circ} \mathrm{C}$ acima de $15^{\circ} \mathrm{C}$, adicionamos 1 ao último número da densidade já obtida."

Por exemplo, se vocês encontrarem uma densidade igual a 1.015 de uma amostra de urina através de um urodensímetro calibrado a $15^{\circ} \mathrm{C}$, e a temperatura da urina for igual a $21^{\circ} \mathrm{C}$, temos $6^{\circ} \mathrm{C}$ de diferença entre as duas temperaturas. Se, para cada $3^{\circ} \mathrm{C}$ de diferença, adicionamos 1 ao último número do valor obtido da densidade, para $6^{\circ} \mathrm{C}$, adicionaremos 2.

Isto significa que, a rigor, a densidade dessa urina será 1.017.

Cabe lembrar que, na prática, este cuidado não é tomado, ou seja, a aplicação desse fator de correção, mas em condições laboratoriais, dispondo de recursos técnicos, isto é possível.

Entretanto, é importante que vocês estejam cientes do que seria, a rigor, uma mensuração correta de densidade urinária.

Pode ocorrer, ainda, que a quantidade de urina disponível não seja suficiente para possibilitar a flutuação do urodensímetro.

Nesse caso, existe também uma solução a que se pode recorrer, ou seja:

- "Dilui-se a amostra de urina disponível em igual volume de água destilada. Mede-se a densidade e, ao expressar-se o resultado, multiplica-se por 20 último ou os dois últimos algarismos."

Ex.: densidade da amostra diluída $=1.012$

densidade real da amostra $=1.024$

Ex.: densidade da amostra diluída $=1.008$

densidade real da amostra $=1.016$

Seria conveniente que vocês fizessem agora algum experimento prático, variando massa e volume da amostra de urina, constatando, assim, a variação zonseqüente da densidade.

Solicitem do professor uma porção de açúcar (massa) e acrescentem-no à urina. Mensurem agora a densidade. Qual é seu valor?

R.:

Desprezem agora metade dessa urina na qual vocês haviam acrescentado açúcar e completem com água o volume desprezado. Mensurem a densidade. Qual o seu valor?

R.: 
BOEMER, M.R. e Colaboradora - Relato de uma experıencia no ensino de verificação da diurese e densidade urinária. Rev. Bras. Enf.; DF, 33 : 404-417, 1980.

Perceberam, então, que a densidade varia conforme a variação da relação massa

volume

Na prática hospitalar, isto ocorrerá também com a urina do paciente. Em uma amostra de urina mais concentrada, ou seja, com maior quantidade de $\frac{\text { massa }}{\text { volume }}$, de densidade será:

$$
\text { maior ( ) menor ( ) }
$$

Em uma urina menos concentrada, ou seja, com maior quantidade de volume (líquido), a densidade será:

maior ( ) menor ( )

Se vocês não estiverem seguros desta prática, solicitem do professor outra folha e repitamı a experiência, procurando não incorrer em erros e/ou omissões cometidos quando da primeira experiência.

\section{ANEXO 2}

\section{ATIVIDADE PRÁTICA - VOLUME E DENSIDADE URINÁRIA}

\section{ROTEIRO - PARTE B}

Na parte A dessa atividade prática, ou seja, medida da diurese e densidade urinária, vocês aprenderam sobre as características a serem observadas na urina e como observar algumas dessas características. Relembraram ainda os valores normais referentes às mesmas.

Para a realização da parte $B$, planejamos uma observação de todas as características de uma amostra de urina no hospital, para aplicação dos conhecimentos já acaquiridos.

A classe será dividida, por nós, em grupos de dez alunos.

Os grupos receberão, com antecedência, a designação do dia e hora em que cada un deverá dirigir-se à Clínica Médica do Hospital das Clínicas para desenvolver essa atividade.

O planejamento dos dias e horários em que cada grupo deverá dirigir-se do hospital ficará, portanto, sob a responsabilidade do professor. Os grupos serão informados desses dias e horários, através da escala fixada no quadro da disciplina.

Uma vez cientes do dia e hora designados a seu grupo, dirijam-se, portanto, à Clínica Médica, uniformizados, pontuais e com caderneta de bolso. Vocês encontrarão um professor esperando por vocês.

- Anotem agora a data e hora de início:

Observem vocês que há várias enfermeiras e nos dirigiremos a qualquer uma delas. Anexo às enfermarias há um banheiro onde ficam guardados os frascos de urina dos pacientes que necessitam, por algum motivo, de uma observação de sua diurese.

Os frascos contém, geralmente, urina correspondente a um período de 24 horas e esse intervalo é computado das 8 horas de um dia às 8 horas do outro dia. 
BOEMER, M.R. e Colaboradora - Relato de uma experiência no ensino de verificação da diurese e densidade urinária. Rev. Bras. Enf.; DF, 33 : 404-417, 1980.

Vamos pegar qualquer frasco e observá-lo.

Existe, neste frasco, alguma identificação?

$$
\operatorname{Sim}(\text { ) Não ( ) }
$$

Se existe, do que consta essa identificação?

Vocês consideram que a identificação está completa?

Sim ( ) Não ( )

Se não está, o que vocês consideram que deveria constar dessa identificação?

Haveria outro(s) frasco(s) do mesmo paciente?

$$
\text { Sim ( ) Não ( ) }
$$

É fácil imaginar que, devido às características sócio-econômicas e culturais \os pacientes, nem todos são alfabetizados. De que modo a enfermagem procederia nesses casos, no que se refere à identificação dos frascos?

Muito bem. Voltemos agora ao(s) frasco(s) que temos em mãos. Quais são as características macroscópicas da urina? Estão normais?

Vamos proceder agora à medida do volume da urina. Vamos transportala, com cuidado, para um cálice graduado, não nos esquecendo de:

- verificar previamente a graduação do cálice;

- despejar a urina com cuidado, vagarosamente, escoando a urina pela parede do cálice;

- colocar o cálice em uma superfície plana;

- adaptar o nível dos nossos olhos ao nível da urina.

ATENÇÃO: Se não foi possível a observância de todos esses cuidados, vamos analisar criticamente os impedimentos.

Qual foi o volume obtido, em mililitros?

R.:

Entāo, este paciente urinou ..... ml em 24 horas.

Este resultado se enquadra nos limites de normalidade?

$$
\operatorname{Sim}(\text { ) Não ( ) }
$$


BOEMER, M.R. e Colaboradora - Relato de uma experiência no ensino de verificação da diurese e densidade urinária. Rev. Bras. Enf.; DF, 33 : 404-417, 1980.

Se não se enquadra, quais os fatores que poderiam estar intervindo?

Vamos medir agora a densidade, de acordo com o que foi ensinado na parte $\mathbf{A}$ dessa atividade.

Resultado:

Este valor se enquadra nos limites de normalidade de densidade urinária?

$$
\text { Sim ( ) Não ( ) }
$$

Se não se enquadra, quais os fatores que podem estar interferindo?

Temos várias informações a respeito dessa diurese e vamos agora anotálas na nossa caderneta de bolso. O professor os orientará quanto ao modo eorreto de anotar. Não se esqueçam de anotar os dados que identificam o paciente.

Podemos agora desprezar essa urina?

$$
\text { Sim ( ) Não ( ) }
$$

Se podemos, onde desprezamos? De que maneira? O que fazer a seguir? cuidado?

Qual o cuidado que devemos ter com o material utilizado? Onde dar esse

Devemos, ainda, ter algum cuidado em relação ao paciente e voltaremos a isso no final desse roteiro.

Muito bem. Aproveitemos, agora, para verificar se existem outros frascos nesse banheiro. Se existirem, manuseiem-nos, observem-nos e vamos extrair mais detalhes dessa nossa atividade.

Notaram alguma coisa que queiram esclarecer?

Se alguém notou, todo grupo deve anotar no espaço abaixo a dúvida do colega, bem como o esclarecimento do professor em relação à dúvida.

Vamos imaginar agora outras situaçбes.

O grupo tentará levantar as situaçōes e o professor complementará, se necessário. Todos anotem essas situaçōes.

No caso de glicosúria fracionada, como faríamos a medida do volume urinário? Para responder a esse item, comecemos por analisar o termo "glicosúria fracionada". O que isto sugere?

Então, como seria feita a medida do volume urinário? Alguém pode dar alguma contribuição?

Anotem as dúvidas, bem como o esclarecimento do professor. 
BOEMER, M.R. e Colaboradora - Relato de uma experiência no ensino de verificação da diurese e densidade urinária. Rev. Bras. Enf.; DF, 33 : 404-417, 1980.

No mesmo caso, ou seja, da glicosúria fracionada, como procederiamos à medida da densidade urinária?

Finalmente, queremos que vocês estejam atentos para certas circunstâncias práticas que ocorrem freqüentemente:

- frasco sem rótulo - como proceder?

- antes de afirmar que há hematúria, no caso de paciente do sexo feminino, certificar-se de que a paciente não está menstruada.

- vidros no banheiro, em quantidade superior ou inferior à necessária, geram confusão.

Podemos agora retirar-nos do banheiro e, como temos anotado a identificação do paciente cuja urina foi observada, vamos procurar seu prontuário no carrinho.

Uma vez localizado o prontuário do paciente, vamos manuseá-lo e verificar onde vamos anotar o que observamos em relação à sua diurese.

Observem que, na folha de gráfico, há um espaço reservado para "urina". Procuramos na parte superior do gráfico a anotação referente ao dia de hoje e anotamos na coluna do dia; no espaço reservado para urina, o volume que medimos em milímetros.

E onde vamos anotar as outras características observadas? Elas são anotadas na folha de observação de enfermagem, obedecendo aos princípios de uma anotação correta, quais sejam:

- precedida de horário

- conteúdo claro e conciso

- sem rasuras

- redação objetiva e em linguagem correta

- assinatura legível de quem fez a anotação.

Vamos então anotar. O professor os ajudará no modo de ridigirem no prontuário do paciente as observações contidas em suas cadernetas de bolso.

Considerando que se espera do enfermeiro profissional algo mais do que uma simples execução da técnica de medida da diurese e densidade urinária, vamos então observar, corrrelacionar e inferir informações que poderão estar associadas com a diurese desse paciente.

Vejamos alguns fatores para os quais devemos estar atentos:

1. Há anotação da diurese do paciente no dia anterior?

$$
\operatorname{Sim}(\text { Não ( ) }
$$

2. Se houver, o volume anotado é maior, menor ou igual ao de hoje?

$$
\text { maior ( ) menor ( ) igual ( ) }
$$

3. Se houver diferença, quais os fatores que poderiam estar interferindo?

4. Há alguma anotação do dia anterior referente à ingestão hídrica desse paciente? Essa anotação seria importante?

5. Vocês consideram importante que se relacione o volume urinàrio que obtivemos com o peso do paciente? Por quê? 
BOEMER, M.R. e Colaboradora - Relato de uma experiência no ensino de verificação da diurese e densidade urinária. Rev. Bras. Enf.; DF, $33: 404-417,1980$.

6. Vocês consideram importante sabermos algo sobre a medicação que o paciente está recebendo, ou seja, isso poderia ter alguma relação com as caracteristicas da diurese?

Agora, solicitem do professor complementaç̃̃o de alguns outros fatores que poderiam estar relacionados com as características que observamos.

7. Alguns pacientes têm necessidade de controle hídrico rigoroso, portanto, todo líquido que recebem ou eliminam deve ser anotado também numa folha especial, denominada folha de controle hidrico; esse cuidado é prescrito pelo médico. Vamos verificar se esse paciente não se enquadra nesse caso, e para tanto devemos consultar a prescrição médica.

Caso haja essa necessidade de controle hídrico, o professor os orientará em como anotar.

Se não houver necessidade, solicitem que o professor lhes mostre uma folha de controle hídrico para que vocês a conheçam.

Finalmente, havíamos dito anteriormente que teríamos algum cuidado em relação a esse paciente no que se refere à diurese, como: urina.

- Certificarmo-nos se o paciente continua necessitando de guardar sua

Caso isso seja necessário, devemos agora:

- Reorientar o paciente em linguagem clara e adequada a seu nível, explicando os motivos e solicitando sua cooperação.

- Verificar de quantos frascos, aproximadamente, ele necessitará. Lembrese de que frascos, em número superior ou inferior ao necessário, geram confusão.

- Identificar seu(s) frasco(s) por símbolos, caso não seja alfabetizado. Manter o mesmo símbolo.

- Avisar o médico, quando julgarmos necesssário, anotando este fato, também, na folha de observação de enfermagem.

Caso não seja mais necessário o controle da diurese, devemos agora:

- Informar o paciente de que não haverá mais necessidade de guardar sua urina, em linguagem clara e adequada a seu nível, explicando os motivos da não necessidade.

- Retirar o(s) seu(s) fraco(s) para evitar confusão.

Administrativamente, é de extrema importância que atentemos para os casos de pacientes que continuam guardando urina, quando não há mais razão de fazê-lo. Isto implica em tempo gasto pelo pessoal de enfermagem para executar a técnica e em material (frascos) utilizados sem motivo. Em síntese, seria a utilização de recursos materiais e humanos em algo desnecessário, talvez em detrimento de algum tipo de assistência necessária, até mesmo de um controle de diurese de algum outro paciente com real necessidade.

Terminamos aqui a parte $\mathrm{B}$ da atividade.

Anotem agora o horário de término: 
BOEMER, M.R. e Colaboradora - Relato de uma experiência no ensino de verificação da diurese e densidade urinária. Rev. Bras. Enf.; DF, 33 : 404-417, 1980.

\section{ANEXO 3 \\ QUESTIONÁRIO}

$O$ ensino da técnica de verificação da diurese e densidade urinária foi ministrado a vocês em roteiros, divididos em parte $\mathrm{A}$ e parte $\mathrm{B}$, no Laboratório e no Hospital respectivamente.

Estamos solicitando, por parte dos alunos, uma avaliação do modo como foi ensinada essa unidade do programa de Fundamentos de Enfermagem.

Por favor, responda com a máxima sinceridade possível o breve questio.. nário abaixo. Não há necessidade de sua identificação.

- Você participou do ensino:

( ) somente da parte A ( ) da parte A e B

( ) somente da parte B ( ) nenhuma

- Você considera que o método de ensino dirigido utilizado foi:

( ) ótimo ( ) razoável

( ) bom ( ) deficiente

- Você considera que aprendeu o que foi ensinado na parte A do roteiro: ( ) $\operatorname{sim}$ ( ) não ( ) razoavelmente

- Você considera que aprendeu o que foi ensinado na parte $\mathrm{E}$ do roteiro: ( ) $\operatorname{sim}($ ( ) não $\quad$ ( ) razoavelmente

- Você considera que o número de alunos por grupo para o ensino da parte A (Laboratório) foi:
( ) ideal
( ) adequado
( ) maior que o desejado
( ) menor que o desejado

- Você considera que o número de alunos por grupo para o ensino da parte B (Hospital) foi:
( ) ideal
( ) adequado

( ) maior que o desejado

( ) menor que o desejado

- Para os próximos anos, você sugere que:

( ) o ensino seja feito da mesma forma

( ) o ensino da parte A seja modificado

( ) o ensino da parte B seja modificado

( ) o ensino de ambas as partes seja modificado.

No caso de modificação, quais são suas sugestōes:

- Você considera que outras unidades do programa possam ser desenvolvidas do mesmo modo?

$$
\text { ( ) } \operatorname{sim}(\text { ) não }
$$

No caso de resposta positiva, mencione as que você gostaria de aprender deste modo:

(Espaço reservado para eventuais comentários sobre esse assunto). 